\title{
Effect of the pressure on the catalytic oxidation of volatile organic compounds over $\mathrm{Ag} / \mathrm{Al}_{2} \mathrm{O}_{3}$ catalyst
}

\author{
Yi Li ${ }^{a}$, Xiuli Zhang ${ }^{a}$, Hong He ${ }^{\mathrm{a}, *}$, Yunbo Yu ${ }^{\mathrm{a}}$, Tao Yuan ${ }^{\mathrm{b}}$, Zhenyu Tian ${ }^{\mathrm{b}}$, Jing Wang ${ }^{\mathrm{b}}$, Yuyang Li $^{\mathrm{b}}$ \\ ${ }^{a}$ Research Center for Eco-Environmental Sciences, Chinese Academy of Sciences, Beijing 100085, PR China \\ ${ }^{\mathrm{b}}$ National Synchrotron Radiation Laboratory, University of Science and Technology of China, Hefei, Anhui 230029, PR China
}

A R T I C L E I N F O

\section{Article history:}

Received 23 September 2008

Received in revised form 5 December 2008

Accepted 28 January 2009

Available online 12 February 2009

Keywords:

Silver/alumina

Volatile organic compounds

Catalytic partial oxidation

Synchrotron VUV photoionization mass

spectrometry

\begin{abstract}
A B S T R A C T
The catalytic oxidation of volatile organic compounds (VOCs: ethanol, 1-propanol and 2-propanol) over $\mathrm{Ag} / \mathrm{Al}_{2} \mathrm{O}_{3}$ catalyst under low and normal atmospheric pressure conditions has been studied with synchrotron vacuum ultraviolet (VUV) photoionization mass spectrometry (PIMS). The partial oxidation intermediates of the VOCs under different pressures were identified by PIMS and their photoionization efficiency (PIE) spectra. Alkene is preferentially formed under the low pressure conditions, while aldehyde and acid are favored under the normal atmospheric pressure conditions. In addition, the low pressure conditions are more suitable for observing the active intermediates, such as ethenol, ketene and propenal. The results indicate that the pressure has a significant effect on the oxidation pathway of VOCs over $\mathrm{Ag} / \mathrm{Al}_{2} \mathrm{O}_{3}$ catalyst.
\end{abstract}

(c) 2009 Elsevier B.V. All rights reserved.

\section{Introduction}

Increasing interest is being shown in catalytic combustion processes, which are convenient ways for the prevention of emission (including the control of nitrogen oxides (NOx) and unburned hydrocarbons in heat and power generation plants) as well as clean-up processes (VOC removal and automobile exhaust converters) [1]. Compared with flame or thermal combustion, catalytic combustion exhibits advantages such as high efficiency, ultra low pollutant emissions, stable combustion, and so on. Fundamental knowledge of catalytic oxidation mechanisms is valuable for the development of effective methods for using catalysts to control air pollution.

The catalytic oxidation of VOCs over various catalysts, as a means to control air pollution, has been investigated [2]. Although silver is not the best oxidation catalyst, it is a well-known catalyst for the conversion of alcohols to aldehydes and ketones, and the only metal that selectively catalyzes ethylene epoxidation to ethylene oxide $[3,4]$. Some researchers have studied the catalytic oxidation of alcohols over silver based catalysts [5-11]. Yao [5] studied the catalytic oxidation of ethanol at low concentrations, and found that nearly $100 \%$ ethanol could be oxidized to acetaldehyde over $\mathrm{Ag} / \mathrm{Al}_{2} \mathrm{O}_{3}$ catalyst, accompanied by a small amount of $\mathrm{CO}, \mathrm{C}_{2} \mathrm{H}_{4}$ and $\mathrm{CH}_{3} \mathrm{COOH}$. Cordi and Falconer [6] studied

\footnotetext{
* Corresponding author. Tel.: +8610 62849123; fax: +861062849123.

E-mail address: honghe@mail.rcees.ac.cn (H. He).
}

the oxidation of five VOCs including methanol, ethanol, acetaldehyde, formic acid and acetic acid over $\mathrm{Ag} / \mathrm{Al}_{2} \mathrm{O}_{3}$ catalyst using temperature-programmed desorption (TPD) and oxidation (TPO). They reported that acetaldehyde and acetic acid were the partial oxidation products of ethanol, while formic acid was the partial oxidation product of methanol.

The selective catalytic reduction (SCR) of NOx by hydrocarbons is a potential method for removing NOx from oxygen rich exhausts of automobiles and stationary combustion facilities. $\mathrm{Ag} / \mathrm{Al}_{2} \mathrm{O}_{3}$ is known to be one of the most effective catalysts for the SCR of NOx by hydrocarbons. He et al. [9-12] found that an enolic surface species could be formed on $\mathrm{Ag} / \mathrm{Al}_{2} \mathrm{O}_{3}$ during the partial oxidation of $\mathrm{CH}_{3} \mathrm{CHO}, \mathrm{C}_{2} \mathrm{H}_{5} \mathrm{OH}, \mathrm{C}_{3} \mathrm{H}_{6}$, 1-propanol and 2-propanol over $\mathrm{Ag} / \mathrm{Al}_{2} \mathrm{O}_{3}$ catalyst using in situ diffuse reflectance infrared Fourier transform spectroscopy (DRIFTS), and found that this highly active species was the key intermediate in the process of NOx reduction by hydrocarbons. Recently, Taatjes et al. [13] studied 24 different flames of 14 prototypical single fuels and low-pressure flames of commercial gasoline using synchrotron VUV photoionization mass spectrometry, and found that enols are common intermediates in hydrocarbon oxidation. It is well known that there is less collision between molecules under low pressure, so that one could expect to obtain rarer partial oxidation intermediates of VOC catalytic oxidation under such reaction conditions. More recently, enols with two to four carbon atoms have been found in propanols and butanols fueled low-pressure flames [14,15]. It is very interesting to note that enols can be formed from low-pressure plasma discharges of alcohols as well [16]. In addition, Ferguson et al. [17] 
reported that elevated pressure could accelerate the oxidation reactions showing that the effect of pressure was important for the investigation of the reaction products.

In this article, the reaction mechanism of catalytic partial oxidation of VOCs (such as ethanol, 1-propanol, and 2-propanol) over $\mathrm{Ag} / \mathrm{Al}_{2} \mathrm{O}_{3}$ catalyst was studied under low and normal atmospheric pressure conditions using tunable synchrotron VUV photoionization mass spectrometry (PIMS) combining with molecularbeam sampling technique. The intermediates of partial oxidation were identified by the measurements of PIMS and photoionization efficiency (PIE) spectra. The results could provide new insights into the mechanisms for the SCR of NOx by alcohols and provide significant contributions to the practical use of $\mathrm{Ag} / \mathrm{Al}_{2} \mathrm{O}_{3}$ catalysts.

\section{Experimental}

\subsection{Catalyst preparation}

\subsubsection{Preparation of $\mathrm{Ag} / \mathrm{Al}_{2} \mathrm{O}_{3}$ powders}

The $4 \% \mathrm{Ag} / \mathrm{Al}_{2} \mathrm{O}_{3}$ catalysts were prepared by an impregnation method using an aqueous solution of silver nitrate. After impregnation, the excess water was removed in a rotary evaporator at $333 \mathrm{~K}$. The samples were first dried at $393 \mathrm{~K}$ for $12 \mathrm{~h}$, followed by calcination at $873 \mathrm{~K}$ for $3 \mathrm{~h}$.

\subsubsection{Preparation of washcoated honeycomb catalysts}

Washcoated honeycomb catalysts were prepared using the $4 \%$ $\mathrm{Ag} / \mathrm{Al}_{2} \mathrm{O}_{3}$ powder. Washcoat slurries were then prepared by mixing $250 \mathrm{~g} \mathrm{Ag} / \mathrm{Al}_{2} \mathrm{O}_{3}$ powder and $750 \mathrm{~g}$ water in a ball mill. Cordierite honeycombs with 400 cells per square inch $(90 \mathrm{~mm}$ in diameter $\times 110 \mathrm{~mm}$ in length) were dipped into the washcoat slips, and excess slurry was blown out with an air knife. The samples were then dried and calcined at $873 \mathrm{~K}$ for $3 \mathrm{~h}$. The washcoat loading was $110 \mathrm{~g}^{-1}$ after calcination.

\subsection{Experimental setup}

The experiments were carried out at National Synchrotron Radiation Laboratory in Hefei, China. A molecular-beam mass spectrometer (MBMS) using synchrotron VUV light as the ionization source provided a novel and selective method for the analysis of individual intermediates and products of the reaction. Synchrotron radiation from a bend magnet of the $800 \mathrm{MeV}$ electron storage ring was monochromized with a 1-m Seya-Namioka monochromator equipped with two gratings (2400 and 1200 grooves $/ \mathrm{mm}$ ), which provided single-photon ionization (SPI) and minimized fragmentation due to the near-threshold ionization. The wavelength of the monochromator was calibrated with the known ionization energies of the inert gases. The energy resolving power $(E / \Delta E)$ was about 500-1000, depending on the slit widths. A LiF window with $1.0 \mathrm{~mm}$ thickness was used to eliminate higher order radiation of the dispersed light in the wavelength region longer than $105 \mathrm{~nm}$.

With the tunability of the light source, a series of mass spectra from 8.63 to $11.15 \mathrm{eV}$ were measured. The measurement time for each mass spectrum was $120 \mathrm{~s}$. The baseline was subtracted from the integrated ion intensity. Each mass peak was integrated to yield the PIE spectra, a plot of ion intensity vs. photon energy. The value of IE could be directly obtained from the PIE spectra. Considering the energy resolution of the monochromator and the cooling effect of molecular beam [18], the experimental error of the measured IEs was less than $0.05 \mathrm{eV}$. Thus, all components could be identified by their molecular weights from the photoionization mass spectrometry near threshold ionization and the ionization energies from photoionization efficiency spectra. The experimental IEs were compared with known literature values. According to our previous studies under the same conditions, the final products of VOCs oxidation over $\mathrm{Ag} / \mathrm{Al}_{2} \mathrm{O}_{3}$ catalyst are $\mathrm{CO}_{2}$ and small amount of CO [10]. In this study, we focused on the intermediates of catalytic partial oxidation of VOCs, which are not in the same magnitude with the final products of $\mathrm{CO}_{2}$ and $\mathrm{CO}$, thereby we did not measure the photoionization efficiency (PIE) spectra of final products.

The details of MBMS have been described elsewhere [18]. It was originally designed for the study of combustion. Some modifications were made to detect products of the catalytic oxidation in this study. In brief, a schematic diagram of the experimental instrument is shown in Fig. 1. A syringe pump (ISCO Inc., USA) was used to control the flow rate of the VOC aqueous solution (ethanol, 1-propanol, and 2-propanol) at $0.500 \mathrm{ml} / \mathrm{min}$. The aqueous
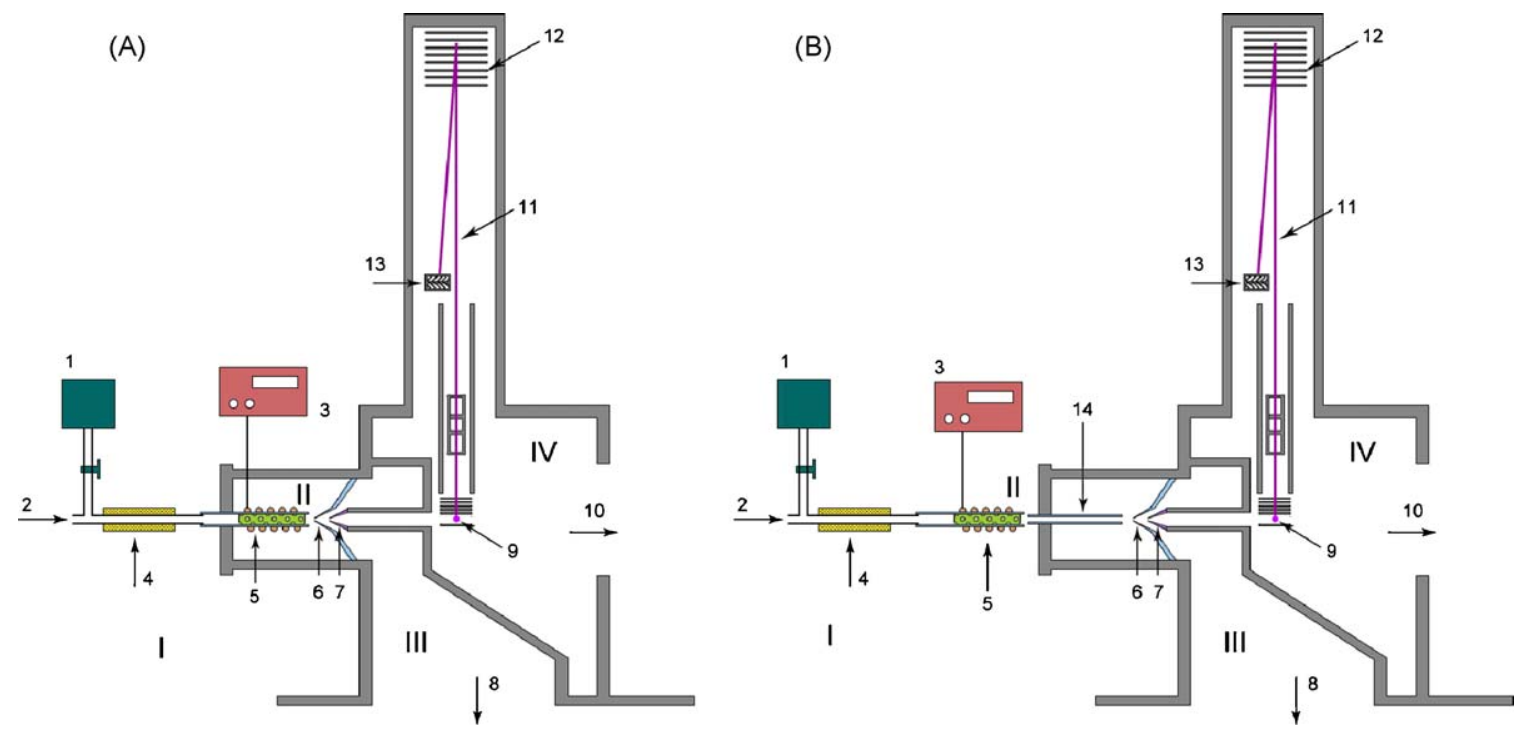

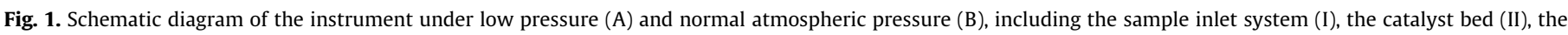

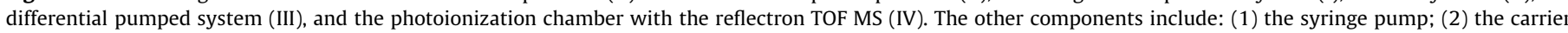

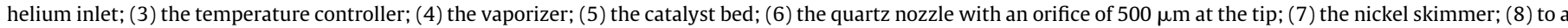

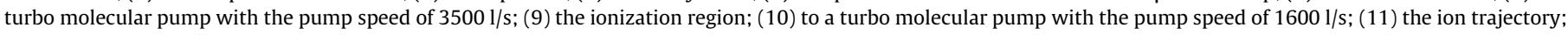
(12) the ion optics of the reflectron; (13) the MCP detector; (14) the quartz sampling tube. 
solution of VOCs was vaporized with the carrier gas $(\mathrm{Ar})$ and passed into the catalyst bed (II). The temperature of the vaporizer was maintained at $423 \mathrm{~K}$ to ensure that the aqueous solution was vaporized completely. As shown in Fig. 1A, the catalyst bed was put in a low-pressure chamber $(\sim 1.07 \mathrm{KPa})$ for the low pressure experiment and just outside the chamber for the experiment under normal atmospheric pressure conditions (Fig. 1B). The temperature of the catalyst bed was controlled by a temperature controller. The appropriate temperatures were adjusted to keep the conversion of VOCs at about 50\%. The flow rates of $\mathrm{Ar}$ and $\mathrm{O}_{2}$ were 1.500 and 0.500 standard liters per minute (SLM), respectively, controlled by a mass flow controller (MKS Instruments Inc.). For the low pressure experiments, the gas-phase mixture of unburned VOCs, partial oxidation products of VOCs and water from the catalyst bed outlet was sampled through a quartz cone-like nozzle with an orifice of $\sim 500 \mu \mathrm{m}$ in diameter. A nickel skimmer with a 2$\mathrm{mm}$ diameter aperture was located at $18 \mathrm{~mm}$ downstream from the sampling nozzle. For the experiments under normal atmospheric pressure conditions, a quartz tube with $2.0 \mathrm{~mm}$ in diameter was used to sample the gases, as shown in Fig. 1B. The sample gases formed a molecular beam, which passed horizontally through the $10 \mathrm{~mm}$ gap between the repeller and extractor plates of the reflectron TOF MS [19]. The molecular beam intersected perpendicularly with the synchrotron VUV light beam. The ion signal was detected with the reflectron TOF MS, which was installed vertically in the photoionization chamber (see Fig. 1). A pulsed voltage of $200 \mathrm{~V}$ was used to propel ions into the flight tube, and finally to a microchannel plate (MCP) detector. Detailed information on the RTOF MS can be found in previous reports $[18,19]$. For the low pressure experiments, the pressures in the sample inlet chamber, the differentially pumped chamber and the ionization chamber were $800,10^{-3}$ and $10^{-3} \mathrm{~Pa}$, respectively. For the experiments under normal atmospheric pressure conditions, the pressures in the sample inlet chamber, the differentially pumped chamber and the ionization chamber were $800,10^{-2}$ and $10^{-3} \mathrm{~Pa}$, respectively.

\section{Results and discussion}

3.1. Catalytic partial oxidation of ethanol over $\mathrm{Ag} / \mathrm{Al}_{2} \mathrm{O}_{3}$ catalyst under low and normal atmospheric pressure conditions

The partial catalytic oxidation of ethanol on the $\mathrm{Ag} / \mathrm{Al}_{2} \mathrm{O}_{3}$ catalyst was conducted at $603 \mathrm{~K}$ under low pressure and at $563 \mathrm{~K}$ under normal atmospheric pressure.

Fig. 2 shows four VUV photoionation mass spectra of the partial oxidation of ethanol on $\mathrm{Ag} / \mathrm{Al}_{2} \mathrm{O}_{3}$ catalyst under low pressure and at different photon energies. Several peaks in the mass range of 20-70 are observed at the photon energy of $10.78 \mathrm{eV}$, which correspond to hydrocarbons ranging from $\mathrm{C}_{2}$ to $\mathrm{C}_{4}$. However, some peaks do not originate from ethanol oxidation. The peaks with odd $\mathrm{m} / \mathrm{z}$ are attributed to ${ }^{13} \mathrm{C}$ isotope contribution. Furthermore, the peaks with odd $\mathrm{m} / \mathrm{z}$ can also be produced from the fragmentation of large hydrocarbons, as the photon energy is high enough to produce fragmentation. In this study, the measurement of the PIE spectra of mass 45 is attributed to the fragmentation of ethanol.

Comparing the experimental IEs with the known values from the literature [20], several kinds of catalytic partial oxidation intermediates are identified. The measured ionization thresholds and ion intensity for all the observed peaks are listed in Table 1. Under low pressure conditions, ethylene, ketene, acetaldehyde, ethenol, propenal, acetone and 2-butenal can be identified; while under normal atmospheric pressure conditions, acetaldehyde, acetone, acetic acid, 2-butenal and ethyl ether are identified. Based on these results, it is obvious that the pressure has a significant effect on the partial catalytic oxidation pathway of ethanol over $\mathrm{Ag} / \mathrm{Al}_{2} \mathrm{O}_{3}$ catalyst.

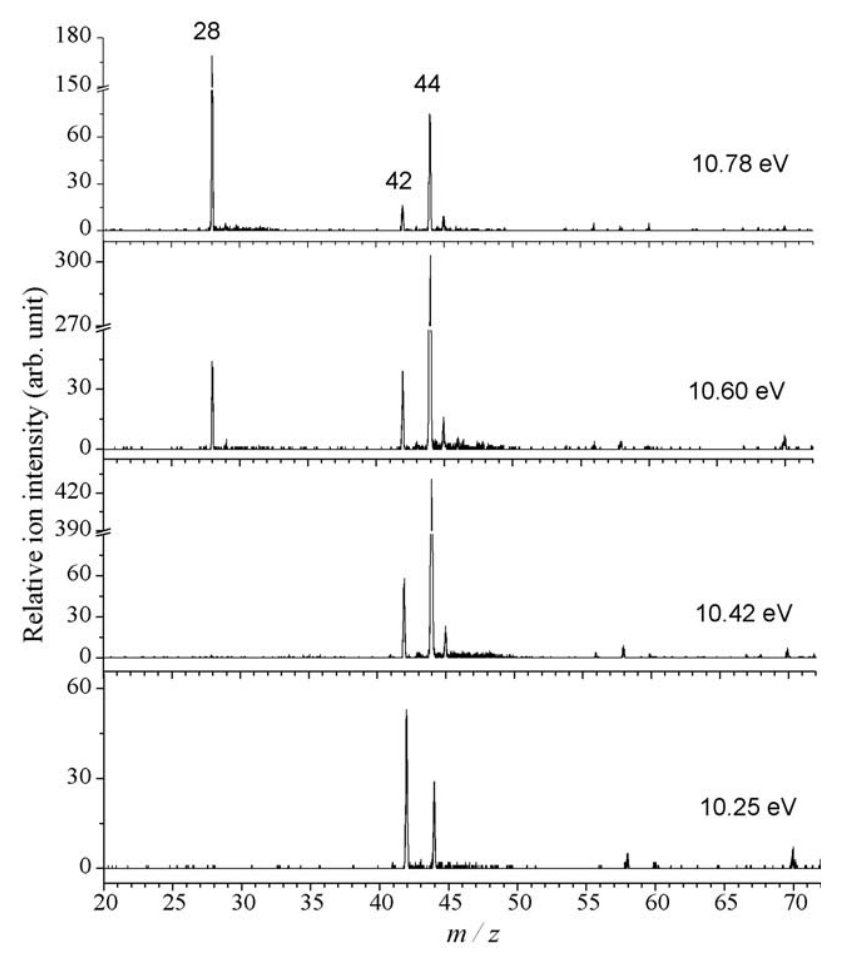

Fig. 2. VUV photoionization mass spectra of partial oxidation of ethanol over Ag/ $\mathrm{Al}_{2} \mathrm{O}_{3}$ catalyst under low pressure at the photon energies of $10.78,10.60,10.42$, and $10.25 \mathrm{eV}$, respectively.

As can be seen in Table 1, acetaldehyde, acetone, and 2-butenal are all present during the partial oxidation of $\mathrm{C}_{2} \mathrm{H}_{5} \mathrm{OH}$ over $\mathrm{Ag} /$ $\mathrm{Al}_{2} \mathrm{O}_{3}$ catalyst under both low and normal atmospheric pressure conditions, and acetaldehyde is the main product with the highest intensity among them. It is considered that acetaldehyde is produced from the dehydrogenation of ethanol over $\mathrm{Ag} / \mathrm{Al}_{2} \mathrm{O}_{3}$ catalyst; acetone is formed by the oxidation of ethanol with molecular oxygen; and 2-butenal is formed from the selfcondensation of acetaldehyde. Based on a previous study [6], acetaldehyde was the main partial oxidation product of ethanol during the TPO experiment and oxygen adsorbed on the silver site activates neighboring silver sites for dehydrogenation, forming acetaldehyde and $\mathrm{H}_{2}$. Yao [5] found that $\mathrm{Ag}$ is a well-known catalyst for the conversion of alcohols to aldehydes and ketones, and nearly $100 \%$ ethanol was oxidized to acetaldehyde over $\mathrm{Ag}$ / $\mathrm{Al}_{2} \mathrm{O}_{3}$ catalysts under appropriate experimental conditions. They also found that acetone was formed by ethanol oxidation with molecular oxygen during the catalytic oxidation of ethanol over $\mathrm{Pd} / \mathrm{Al}_{2} \mathrm{O}_{3}$ catalysts. Furthermore, the aldol condensation reaction is an important method for the synthesis of unsaturated carbonyl compounds in organic chemistry.

The ethylene, ketene, ethenol and propenal in Table 1 are only identified under low pressure conditions, whereas only acetic acid and ethyl ether are identified under normal atmospheric pressure conditions. Ethenol, as the isomer of acetaldehyde, has the same molecular weight as acetaldehyde and is only observed under low pressure conditions. Here the ethenol and acetaldehyde can be differentiated by comparing their different IEs from the PIE spectra with literature values. The PIE spectra of $m / z=44\left(\mathrm{C}_{2} \mathrm{H}_{4} \mathrm{O}\right)$ (Fig. 3) illustrate how to identify the isomers. Under low pressure, two onsets are clearly observed at 9.33 and $10.21 \mathrm{eV}$, which correspond to the IEs of ethenol and acetaldehyde according to the literature values of $9.33 \pm 0.01$, and $10.21 \pm 0.01 \mathrm{eV}$ [20]. Ethenol $\left(\mathrm{CH}_{2}=\mathrm{HC}-\right.$ $\mathrm{OH}$ ), bearing $\mathrm{OH}$ groups adjacent to carbon-carbon double bonds, is thermodynamically unstable relative to acetaldehyde $\left(\mathrm{CH}_{3}-\mathrm{HC}=\mathrm{O}\right)$. Until now, only a few experimental data are available on neutral enol 
Table 1

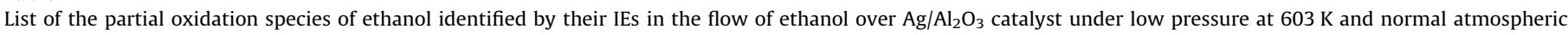
pressure at $563 \mathrm{~K}$.

\begin{tabular}{|c|c|c|c|c|c|c|c|}
\hline \multirow[t]{2}{*}{$m / z$} & \multirow[t]{2}{*}{ Formula } & \multicolumn{2}{|l|}{ Low pressure } & \multicolumn{2}{|c|}{ Normal atmospheric pressure } & \multirow[t]{2}{*}{ Species } & \multirow[t]{2}{*}{ Ref. [20] } \\
\hline & & Measured $( \pm 0.05 \mathrm{eV})$ & Ion intensity (arb. unit) & Measured $( \pm 0.05 \mathrm{eV})$ & Ion intensity (arb. unit) & & \\
\hline 28 & $\mathrm{C}_{2} \mathrm{H}_{4}$ & 10.52 & 22.46 & - & - & Ethylene & $10.50 \pm 0.02$ \\
\hline 42 & $\mathrm{C}_{2} \mathrm{H}_{2} \mathrm{O}$ & 9.62 & 7.49 & - & - & Ketene & $9.614 \pm 0.008$ \\
\hline \multirow[t]{2}{*}{44} & $\mathrm{C}_{2} \mathrm{H}_{4} \mathrm{O}$ & 10.21 & 67.37 & 10.21 & 87.72 & Acetaldehyde & $10.21 \pm 0.01$ \\
\hline & $\mathrm{C}_{2} \mathrm{H}_{4} \mathrm{O}$ & 9.33 & 0.90 & - & - & Ethenol & $9.33 \pm 0.01$ \\
\hline 56 & $\mathrm{C}_{3} \mathrm{H}_{4} \mathrm{O}$ & 10.11 & 0.45 & - & - & Propenal & $10.10 \pm 0.01$ \\
\hline 58 & $\mathrm{C}_{3} \mathrm{H}_{6} \mathrm{O}$ & 9.7 & 0.45 & 9.7 & 0.88 & Acetone & $9.71 \pm 0.01$ \\
\hline 60 & $\mathrm{C}_{2} \mathrm{H}_{4} \mathrm{O}_{2}$ & - & - & 10.65 & 6.58 & Acetic acid & $10.66 \pm 0.05$ \\
\hline 70 & $\mathrm{C}_{4} \mathrm{H}_{6} \mathrm{O}$ & 9.74 & 0.90 & 9.74 & 2.19 & 2-Butenal & $9.73 \pm 0.01$ \\
\hline 74 & $\mathrm{C}_{4} \mathrm{H}_{10} \mathrm{O}$ & - & - & 9.53 & 2.63 & Ethyl ether & $9.53 \pm 0.02$ \\
\hline
\end{tabular}

chemistry. In the low-pressure flames of hydrocarbon oxidation, Taatjes et al. [13] found that enols are the common intermediates in hydrocarbon oxidation. Qi et al. $[14,15]$ found that enols with two to four carbon atoms were in propanols and butanols fueled flames. Also, it is very interesting that enols can also be formed from plasma discharges of alcohols [16]. Under normal pressure, He et al. [9-12] observed the formation of the enolic species during the partial oxidation of alcohols on $\mathrm{Ag} / \mathrm{Al}_{2} \mathrm{O}_{3}$ catalyst using in situ DRIFTS measurements, where the $\mathrm{Ag} / \mathrm{Al}_{2} \mathrm{O}_{3}$ could provide a suitable surface to stabilize the ethenol. In the case of catalytic oxidation of ethanol over $\mathrm{Ag} / \mathrm{Al}_{2} \mathrm{O}_{3}$, we deduce that $\mathrm{C}_{2} \mathrm{H}_{5} \mathrm{OH}$ is first adsorbed on the surface of $\mathrm{Ag} / \mathrm{Al}_{2} \mathrm{O}_{3}$, an enolic anion $\left(\mathrm{CH}_{2}=\mathrm{CH}-\mathrm{O}\right)^{-} \mathrm{M}^{+}$is then formed on the surface via the dehydrogenation of $\mathrm{C}_{2} \mathrm{H}_{5} \mathrm{OH}$. A part of the enolic anion subsequently desorbs from the $\mathrm{Ag} / \mathrm{Al}_{2} \mathrm{O}_{3}$ catalyst, becoming gaseous ethenol. Owing to its thermodynamic instability under normal pressure, ethenol subsequently transforms rapidly into acetaldehyde. Therefore, we consider that ethenol is the key intermediate during the catalytic partial oxidation of $\mathrm{C}_{2} \mathrm{H}_{5} \mathrm{OH}$ on the $\mathrm{Ag} / \mathrm{Al}_{2} \mathrm{O}_{3}$ catalyst, and the formation of ethenol is significant for the SCR of NOx by $\mathrm{C}_{2} \mathrm{H}_{5} \mathrm{OH}$ over the $\mathrm{Ag} / \mathrm{Al}_{2} \mathrm{O}_{3}$ catalyst. In contrast, under normal atmospheric pressure conditions, ethenol cannot be observed in gas phase. However, in our previous study [9-12], we found that an enolic surface species was formed on $\mathrm{Ag} / \mathrm{Al}_{2} \mathrm{O}_{3}$ under normal pressure during the partial oxidation of $\mathrm{CH}_{3} \mathrm{CHO}, \mathrm{C}_{2} \mathrm{H}_{5} \mathrm{OH}, \mathrm{C}_{3} \mathrm{H}_{6}$, 1-propanol and 2-propanol over $\mathrm{Ag} / \mathrm{Al}_{2} \mathrm{O}_{3}$ catalyst by in situ DRIFTS measurement. Therefore, we conclude that ethenol is formed on the surface of $\mathrm{Ag} / \mathrm{Al}_{2} \mathrm{O}_{3}$ catalyst, but desorbed ethenol subsequently transforms rapidly into acetaldehyde in gas phase so that it cannot be detected even using

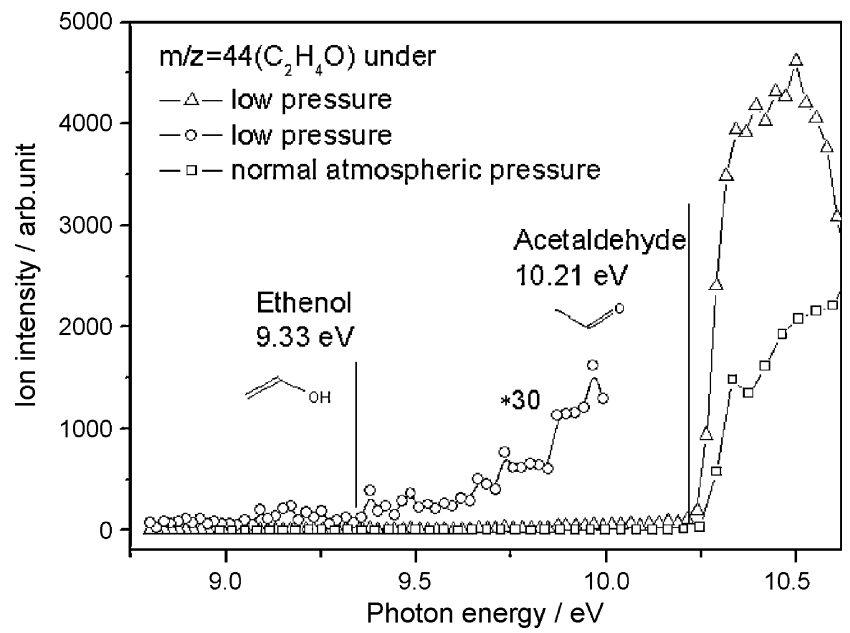

Fig. 3. The PIE spectra of $m / z=44\left(\mathrm{C}_{2} \mathrm{H}_{4} \mathrm{O}\right)$ measured in the flow of ethanol over $\mathrm{Ag} /$ $\mathrm{Al}_{2} \mathrm{O}_{3}$ catalyst under low pressure at $603 \mathrm{~K}$ and normal atmospheric pressure at $563 \mathrm{~K}$. synchrotron VUV photoionization mass spectrometry under normal pressure conditions.

Besides ethenol, the ethylene, ketene and propenal can only be identified under low pressure conditions. It is deduced that ethylene is formed by the dehydration of ethanol over $\mathrm{Ag} / \mathrm{Al}_{2} \mathrm{O}_{3}$ catalyst. Because of its high intensity, the formation of ethylene is another main reaction pathway for the partial oxidation of ethanol over $\mathrm{Ag} / \mathrm{Al}_{2} \mathrm{O}_{3}$ catalyst under low pressure conditions. It is also supposed that ketene is formed by the further dehydrogenation of acetaldehyde and the formation of propenal is a result of the rearrangement and further dehydrogenation of acetone. According to the literature [6], ethylene may be formed by dehydration of ethanol on $\mathrm{Al}_{2} \mathrm{O}_{3}$.

On the other hand, acetic acid and ethoxy ethane are only observed under normal atmospheric pressure, as shown in Table 1. It is supposed that acetic acid is formed by the further oxidation of the generated acetaldehyde and ethyl ether is formed by the intermolecular dehydration of ethanol. In organic chemistry, the catalytic oxidation of aldehydes to the corresponding carboxylic acids is an important method for the preparation of acetic acid. Furthermore, in industrial applications, ethanol can be dehydrated to form ethyl ether on $\mathrm{Al}_{2} \mathrm{O}_{3}$ with more than 95\% yield under suitable reaction conditions.

On the basis of the above results, we can conclude that pressure significantly affects the formation pathway of the partial oxidation intermediates on $\mathrm{Ag} / \mathrm{Al}_{2} \mathrm{O}_{3}$ catalyst, as shown in Scheme 1. The low pressure conditions favor the dehydration and dehydrogenation of ethanol over the $\mathrm{Ag} / \mathrm{Al}_{2} \mathrm{O}_{3}$ catalyst. However, normal atmospheric pressure conditions favor the partial catalytic oxidation of ethanol. In addition, low pressure conditions favor the observation of active intermediates, such as ethenol, ketene and propenal, and the

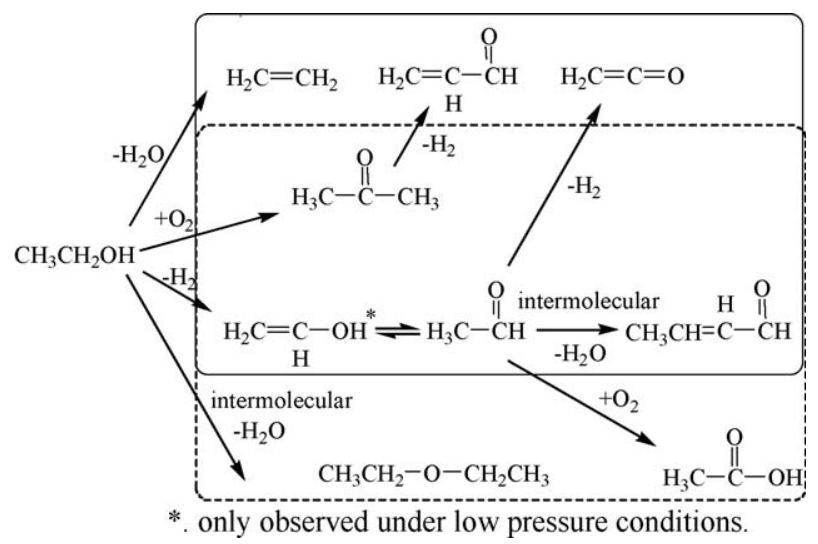

Scheme 1. Possible formation pathways of ethanol partial oxidation intermediates over $\mathrm{Ag} / \mathrm{Al}_{2} \mathrm{O}_{3}$ catalyst under low pressure at $603 \mathrm{~K}$ (solid frame) and normal atmospheric pressure at $563 \mathrm{~K}$ (dotted frame). 
Table 2

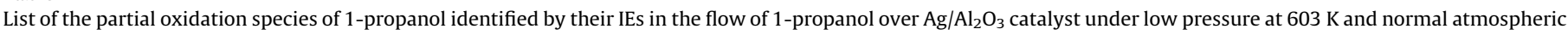
pressure at $523 \mathrm{~K}$.

\begin{tabular}{|c|c|c|c|c|c|c|c|}
\hline \multirow[t]{2}{*}{$m / z$} & \multirow[t]{2}{*}{ Formula } & \multicolumn{2}{|l|}{ Low pressure } & \multicolumn{2}{|c|}{ Normal atmospheric pressure } & \multirow[t]{2}{*}{ Species } & \multirow[t]{2}{*}{ Ref. [20] } \\
\hline & & Measured $( \pm 0.05 \mathrm{eV})$ & Ion intensity (arb. unit) & Measured $( \pm 0.05 \mathrm{eV})$ & Ion intensity (arb. unit) & & \\
\hline 28 & $\mathrm{C}_{2} \mathrm{H}_{4}$ & 10.5 & 5.85 & - & - & Ethylene & $10.50 \pm 0.02$ \\
\hline 42 & $\mathrm{C}_{3} \mathrm{H}_{6}$ & 9.73 & 70.26 & - & - & Propene & $9.73 \pm 0.01$ \\
\hline 44 & $\mathrm{C}_{2} \mathrm{H}_{4} \mathrm{O}$ & - & - & 10.2 & 4.62 & Acetaldehyde & $10.21 \pm 0.01$ \\
\hline 56 & $\mathrm{C}_{3} \mathrm{H}_{4} \mathrm{O}$ & 8.95 & 3.75 & - & - & Propenal & 8.95 \\
\hline 58 & $\mathrm{C}_{3} \mathrm{H}_{6} \mathrm{O}$ & 9.96 & 16.39 & 9.96 & 86.71 & Propanal & 9.96 \\
\hline 74 & $\mathrm{C}_{3} \mathrm{H}_{6} \mathrm{O}_{2}$ & - & - & 10.21 & 8.67 & Propanoic acid & $10.24 \pm 0.03$ \\
\hline 78 & $\mathrm{C}_{6} \mathrm{H}_{6}$ & 9.21 & 3.75 & - & - & Benzene & $9.2 \pm 0.1$ \\
\hline
\end{tabular}

formation of ethenol is a key step during the catalytic oxidation of $\mathrm{C}_{2} \mathrm{H}_{5} \mathrm{OH}$ over the $\mathrm{Ag} / \mathrm{Al}_{2} \mathrm{O}_{3}$ catalyst.

3.2. Catalytic partial oxidation of 1-propanol and 2-propanol over Ag/ $\mathrm{Al}_{2} \mathrm{O}_{3}$ catalyst under low and normal atmospheric pressure conditions

To further investigate the effect of the pressure on the formation pathway of the partial oxidation products on $\mathrm{Ag} /$ $\mathrm{Al}_{2} \mathrm{O}_{3}$ catalyst, we also studied the catalytic partial oxidation of 1propanol and 2-propanol over the catalyst. The catalytic partial oxidation of 1-propanol was carried out at $603 \mathrm{~K}$ under low pressure and $523 \mathrm{~K}$ under normal atmospheric pressure. The measured ionization thresholds and ion intensity for all observed peaks are listed in Table 2, along with the IEs from the literature [20].

Under low pressure conditions, ethylene, propene, propenal, propanal and benzene are identified, whereas acetaldehyde, propanal, and propanoic acid are identified under normal atmospheric pressure conditions. The formation pathways of the 1propanol partial oxidation intermediates over $\mathrm{Ag} / \mathrm{Al}_{2} \mathrm{O}_{3}$ catalyst are shown in Scheme 2.

Comparing the results under low pressure with those under normal atmospheric pressure in Table 2, only propanal is the common partial oxidation intermediate formed by the dehydrogenation of 1-propanol. The PIE spectra for propanal under both low and normal atmospheric pressure conditions are shown in Fig. 4. Under normal atmospheric pressure, propanal shows the highest signal intensity, indicating that it is the main intermediate of the partial oxidation of 1-propanol over $\mathrm{Ag} /$ $\mathrm{Al}_{2} \mathrm{O}_{3}$ catalyst. As shown in Table 2, ethylene, propene, propenal and benzene are only observed under low pressure. It is deduced that propenal is formed by the further dehydrogenation of propanal. Propene is formed by the dehydration of 1-propanol and shows the highest intensity, indicating that propene is the

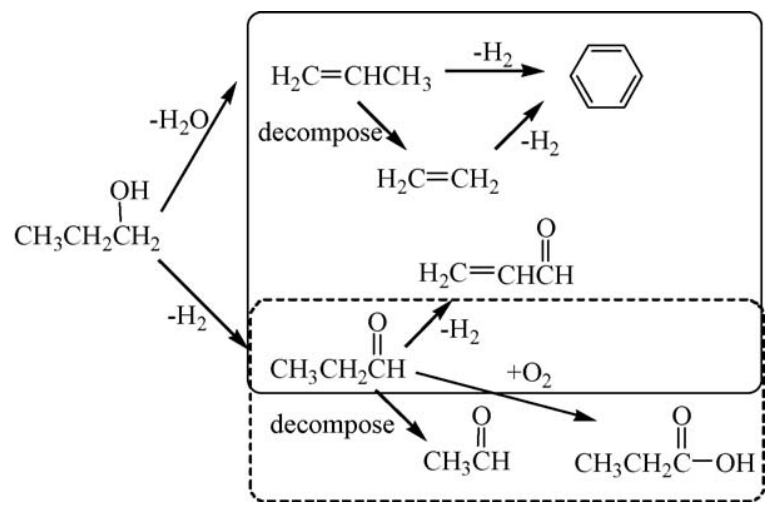

Scheme 2. Possible formation pathways of 1-propanol partial oxidation intermediates over $\mathrm{Ag} / \mathrm{Al}_{2} \mathrm{O}_{3}$ catalyst under low pressure at $603 \mathrm{~K}$ (solid frame) and normal atmospheric pressure at $523 \mathrm{~K}$ (dotted frame). main intermediate of 1-propanol partial oxidation over $\mathrm{Ag} / \mathrm{Al}_{2} \mathrm{O}_{3}$ catalyst. Subsequently, a part of propene decomposes to ethylene. Trace amounts of benzene are formed by further dehydrogenation and condensation of ethylene or propene or both. Under normal atmospheric pressure, only acetaldehyde and propanoic acid are observed. The formation of acetaldehyde can be explained by the decomposition of propanal over $\mathrm{Ag} /$ $\mathrm{Al}_{2} \mathrm{O}_{3}$ catalyst, and propanoic acid is formed by the further oxidation of propanal.

A similar experiment was performed for the catalytic partial oxidation of 2-proponal over $\mathrm{Ag} / \mathrm{Al}_{2} \mathrm{O}_{3}$ catalyst at $603 \mathrm{~K}$ under low pressure and at $473 \mathrm{~K}$ under normal atmospheric pressure. The measured ionization thresholds and ion intensities for all observed peaks are listed in Table 3, along with the IEs from the literature [20].

Under low pressure conditions, propene, acetaldehyde, acetone, methylethyl ether and benzene are identified, whereas only acetone appears under normal atmospheric pressure conditions. The formation pathways of the partial oxidation intermediates of 2-propanol over $\mathrm{Ag} / \mathrm{Al}_{2} \mathrm{O}_{3}$ catalyst are shown in Scheme 3.

The results in Table 3 show that acetone is the common partial oxidation intermediate, formed by the dehydrogenation of 2propanol. The PIE spectra for acetone are shown in Fig. 5, its high intensity indicating that the formation of acetone is the main reaction pathway in the partial oxidation of 2-propanol over $\mathrm{Ag}$ / $\mathrm{Al}_{2} \mathrm{O}_{3}$ catalyst under low and normal atmospheric pressure conditions.

Under low pressure conditions, the other four products are observed, that is, propene, acetaldehyde, methylethyl ether and benzene. The formation of propene with high intensity can be

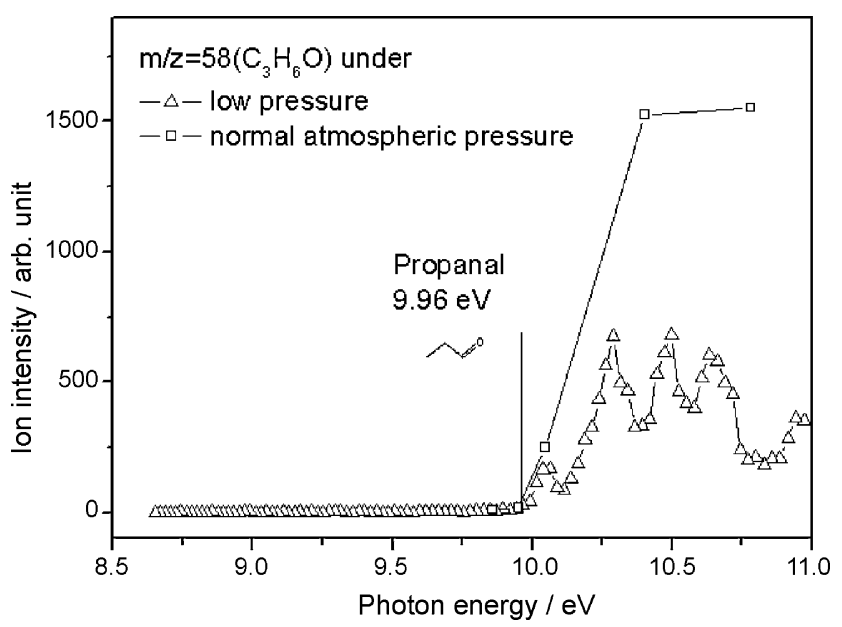

Fig. 4. The PIE spectra for $m / z=58\left(\mathrm{C}_{3} \mathrm{H}_{6} \mathrm{O}\right)$ measured in the flow of 1-propanol over $\mathrm{Ag} / \mathrm{Al}_{2} \mathrm{O}_{3}$ catalyst under low pressure at $603 \mathrm{~K}$ and normal atmospheric pressure at $523 \mathrm{~K}$ 
Table 3

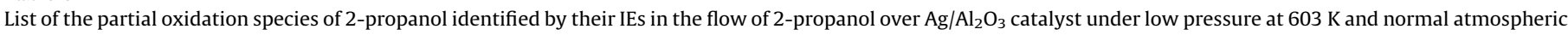
pressure at $473 \mathrm{~K}$

\begin{tabular}{|c|c|c|c|c|c|c|c|}
\hline \multirow[t]{2}{*}{$m / z$} & \multirow[t]{2}{*}{ Formula } & \multicolumn{2}{|l|}{ Low pressure } & \multicolumn{2}{|c|}{ Normal atmospheric pressure } & \multirow[t]{2}{*}{ Species } & \multirow[t]{2}{*}{ Ref. [20] } \\
\hline & & Measured $( \pm 0.05 \mathrm{eV})$ & Ion intensity (arb. unit) & Measured $( \pm 0.05 \mathrm{eV})$ & Ion intensity (arb. unit) & & \\
\hline 42 & $\mathrm{C}_{3} \mathrm{H}_{6}$ & 9.73 & 21.34 & - & - & Propene & $9.73 \pm 0.01$ \\
\hline 44 & $\mathrm{C}_{2} \mathrm{H}_{4} \mathrm{O}$ & 10.21 & 2.78 & - & - & Acetaldehyde & $10.21 \pm 0.01$ \\
\hline 58 & $\mathrm{C}_{3} \mathrm{H}_{6} \mathrm{O}$ & 9.69 & 74.21 & 9.70 & 100.00 & Acetone & $9.69 \pm 0.01$ \\
\hline 60 & $\mathrm{C}_{3} \mathrm{H}_{8} \mathrm{O}$ & 9.7 & 0.93 & - & - & Methylethyl ether & $9.6 \pm 0.1$ \\
\hline 78 & $\mathrm{C}_{6} \mathrm{H}_{6}$ & 9.21 & 0.74 & - & - & Benzene & $9.2 \pm 0.1$ \\
\hline
\end{tabular}

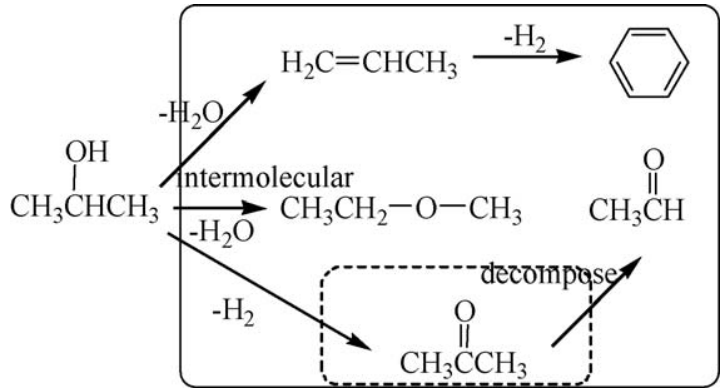

Scheme 3. Possible formation pathways of the 2-propanol partial oxidation intermediates over $\mathrm{Ag} / \mathrm{Al}_{2} \mathrm{O}_{3}$ catalyst under low pressure at $603 \mathrm{~K}$ (solid frame) and normal atmospheric pressure at $473 \mathrm{~K}$ (dotted frame).

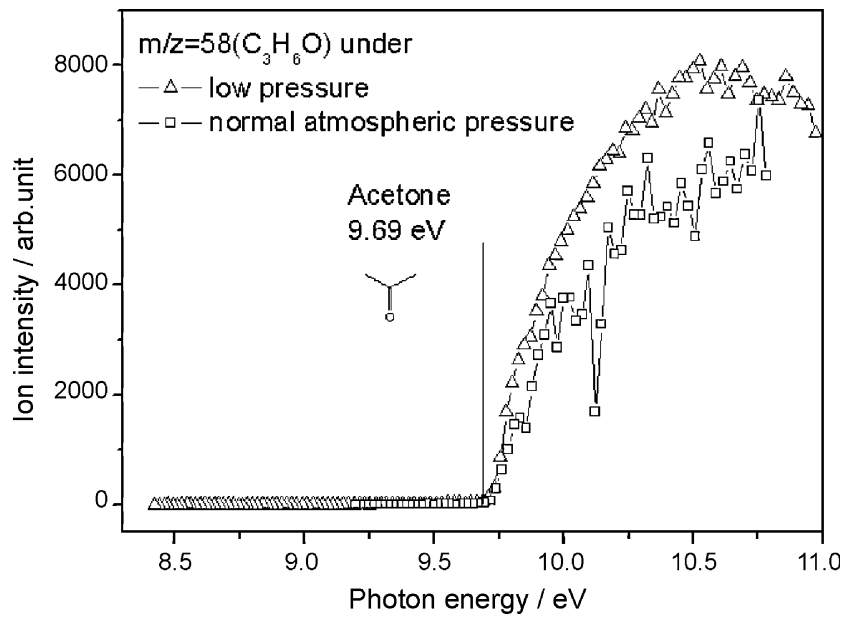

Fig. 5. The PIE spectra for $m / z=58\left(\mathrm{C}_{3} \mathrm{H}_{6} \mathrm{O}\right)$ measured in the flow of 2-propanol over $\mathrm{Ag} / \mathrm{Al}_{2} \mathrm{O}_{3}$ catalyst under low pressure at $603 \mathrm{~K}$ and normal atmospheric pressure at $473 \mathrm{~K}$.

explained by the dehydration of the adsorbed 2-propanol over Ag/ $\mathrm{Al}_{2} \mathrm{O}_{3}$ catalyst, which is another main reaction pathway of the partial oxidation of 2-propanol on $\mathrm{Ag} / \mathrm{Al}_{2} \mathrm{O}_{3}$ catalyst under low pressure. Subsequently, trace amounts of benzene are formed by further dehydrogenation and condensation of propene. It is also supposed that methylethyl ether is formed by the intermolecular dehydration and decomposition of 2-propanol. Further decomposition may produce acetaldehyde.

Based on these results, it is noteworthy that the pressure has a significant effect on the formation pathway of the partial oxidation products of 1-propanol and 2-propanol over $\mathrm{Ag} / \mathrm{Al}_{2} \mathrm{O}_{3}$ catalyst. Low pressure conditions favor the dehydration and dehydrogenation of 1-propanol and 2-propanol over the $\mathrm{Ag} / \mathrm{Al}_{2} \mathrm{O}_{3}$ catalyst. In contrast, normal atmospheric pressure conditions favor the partial oxidation of 1-propanol and 2-propanol. In addition, low pressure conditions favor observation of active intermediates such as propenal.

\section{Conclusions}

Synchrotron VUV photoionization mass spectrometry combined with a molecular-beam sampling technique has been used to study the partial catalytic oxidation of volatile organic compounds (ethanol, 1-propanol and 2-propanol) over $\mathrm{Ag} / \mathrm{Al}_{2} \mathrm{O}_{3}$ catalyst under low pressure and normal atmospheric pressure conditions. It was found that the pressure has a significant effect on the reaction pathways for the partial oxidation of the VOCs. Low pressure conditions favor the dehydration and dehydrogenation of VOCs over the $\mathrm{Ag} / \mathrm{Al}_{2} \mathrm{O}_{3}$ catalyst, and normal atmospheric pressure conditions favor the further partial oxidation of the VOCs. In addition, ethenol, ketene and propenal can be unambiguously identified as active reaction intermediates under low pressure conditions. For the oxidation of ethanol, the formation of ethenol is a key step during the catalytic oxidation of $\mathrm{C}_{2} \mathrm{H}_{5} \mathrm{OH}$ on the $\mathrm{Ag} / \mathrm{Al}_{2} \mathrm{O}_{3}$ catalyst under both low pressure and normal atmospheric pressure conditions.

\section{Acknowledgements}

Authors are grateful to Prof. Fei Qi for experimental design and modification. This work was financially supported by the National Natural Science Foundation of China (20773158) and the Ministry of Science and Technology of China (2007AA061402 and 2007DFA61310).

\section{References}

[1] R.L. Garten, R.A. Dalla Betta, J.C. Schlatter, in: G. Ertl, H. Knozinger, J. Wertkamp (Eds.), Handbook of Heterogeneous Catalysis, vol. 4, VCH, Weinheim, Germany, 1998, p. 1668.

[2] J.J. Spivey, Ind. Eng. Chem. Res. 26 (1987) 2165-2180.

[3] M.C.N.A. Carvalho, F.B. Passos, M. Schmal, J. Catal. 248 (2007) 124-129.

[4] A. Ayame, Y. Uchida, H. Ono, M. Miyamoto, T. Sato, H. Hayasaka, Appl. Catal. A 244 (2003) 59-70

[5] Y.-F. Yu Yao, Ind. Eng. Chem. Proc. Des. Dev. 23 (1984) 60-67.

[6] E.M. Cordi, J.L. Falconer, Appl. Catal. A 151 (1997) 179-191.

[7] W. Wang, H.B. Zhang, G.D. Lin, Z.T. Xiong, Appl. Catal. B 24 (2000) 219-232.

[8] J. Shen, W. Shan, Y.H. Zhang, J.M. Du, H.L. Xu, K.N. Fan, W. Shen, J. Catal. 237 (2006) 94-101.

[9] Y. Yu, H. He, Q. Feng, J. Phys. Chem. B 107 (2003) 13090-13092.

[10] Y. Yu, H. Gao, H. He, Catal. Today 93-95 (2004) 805-809.

[11] Q. Wu, H. He, Y. Yu, Appl. Catal. B 61 (2005) 107-113.

[12] H. He, X. Zhang, Q. Wu, C. Zhang, Y. Yu, Catal. Surv. Asia 12 (2008) 38-55.

[13] C.A. Taatjes, N. Hansen, A. McIlroy, J.A. Miller, J.P. Senosianin, S.J. Klippenstein, F. Qi, L.S. Sheng, Y.W. Zhang, T.A. Cool, J. Wang, P.R. Westmoreland, M.E. Law, T. Kasper, K. Kohse-Höinghaus, Science 308 (2005) 1887-1889.

[14] Y.Y. Li, L.X. Wei, Z.Y. Tian, B. Yang, J. Wang, T.C. Zhang, F. Qi, Combust. Flame 152 (2008) 336-359.

[15] B. Yang, P. Oßwald, Y.Y. Li, J. Wang, L.X. Wei, Z.Y. Tian, F. Qi, K. Kohse-Höinghaus, Combust. Flame 148 (2007) 198-209.

[16] J. Wang, Y.Y. Li, T.C. Zhang, Z.Y. Tian, B. Yang, K.W. Zhang, F. Qi, A.G. Zhu, Z.F. Cui, C.Y. Ng, Astrophys. J. 676 (2008) 416-419.

[17] H.A. Ferguson, S.A. Mehta, R.G. Moore, N.E. Okazawa, M.G. Ursenbach, J. Can. Petrol. Technol. 45 (2006) 49-55.

[18] F. Qi, R. Yang, B. Yang, C.Q. Huang, L.X. Wei, J. Wang, L.S. Sheng, Y.W. Zhang, Rev. Sci. Instrum. 77 (2006) 084101

[19] C.Q. Huang, B. Yang, R. Yang, J. Wang, L.X. Wei, X.B. Shan, L.S. Sheng, Y.W. Zhang, F. Qi, Rev. Sci. Instrum. 76 (2005) 126108.

[20] P.J. Linstrom, W.G. Mallard, NIST Chemistry Webbook, NIST Standard Reference Database Number 69, National Institute of Standards and Technology, Gaithersburg, MD, 2003, http://webbook.nist.gov. 